Kohl: a Journal for Body and Gender Research

Vol. 2, No. 1 (Summer 2016)

\title{
Mount Mound Refuse
}

Jessika Khazrik 
104 I've invited a film crew to break into my parents' house and tear down a wall in the living room.

I only wanted a piece a small piece to

test.

A sample so i

Dug my back

Took a skin took the stone Left the wall, called

a lab.

Sort and lot, come on in, bring It on,

We'll make furniture out of your ragged

Shoes and clothes, workers expired smirched uniform

Yellow uniform turn into

Blue, fire but do not smell, red

Uniforms turn into black, sell, we'll

Pay the money if you take what we expel.

The way i looked at her and told

Her i am so many things not so human at all that my hair

Is a scion of vine, jeans, and wind swat, a wall

That when $\mathrm{R} \_0$ steals my face my glottis

Glides in, thrusts up rocks my neck like a tumbling bell, a herald a wolf steals your face and sings aa a aaa aaaa in your head .

A triangle enters a circle and breeds.

It will not stand still it

Will not stand still. I am looking for

Words that do not function in stones

Extracted, buried and

Turned. Into buildings highways

Fantasies of a city reconstructed

After war, dirt, a forest is

A factory of dreams of halted witnesses

Dead from material for

Money distributed near friends.

From the depths of this vast yet finite forest I saw us

Coming.

I, Little Arsonist and R_O in

From the depths of this vast yet finite forest whose limits

We Have noted before coming 
Here but have in this moment forgotten, the rattling sound

Of beasts, of our feet the soft thuds and whispers

Could be heard. It

Accelerated, stopped then relapsed in all directions. Was

Little Arsonist murmuring or was it $\mathrm{R} \_0$ ? I

Strangely could not discern between

The two voices i was most

Familiar with, or perhaps my own? We were used

To being alone together, but not in a

Forest, not in this one.

this is the Arabic title, you could now write poetry. حقل في أكوام القمامة

HCBD HCBD

Hurling Calmly Between Dirt

Hamstrings Climbing Barrels' Debt

hello Come Baby Dance

hello Come Baby Dance

All the chemical formulas we turned into poetry

Hurling Calmly Between Durt

It will not stand still it

Will not stand still. I am looking for

Words that do not function in stones

Extracted, buried and

Turned. Into buildings highways

Fantasies of a city reconstructed

After war, dirt, a forest is

A factory of dreams of halted witnesses

Dead from material for

Money distributed near body and friends.

A thirsty hunter stood beneath a hole

A wolf glanced at him and never passed

Black rendered blue barrel fat

${ }^{1}$ ḥaqlun fĩ 2akwam el qumamaaaaaaaaaaaaaaaaa 
Kohl 2.1

Little Arsonist لم تكن تستمع

Waste installed on stone

The Lebanese Forces stood beneath a hole

A route of beautiful wolves glanced at them briefly

A صياد said

"we are not a secret"

it 2it tit it

Missing Mountain blared

Black rendered blue barrel fat

Little Arsonist

"Why were wastes installed on stones?"

A forestslept in a hole

Hyenas glanced at us tautly

Little Arsonist

Don't think we were waiting for

Something else to be filling our words in this forest

Arthritic roads

Dioxins sulking under soil

In concrete

In buildings

Reconstructions

Beirut

My parents' house

Hurling Calmly Between Dirt

$\mathrm{AgCN}$

Now we knew that

These militias even feared

Music

$\mathrm{HAH}$

Our words remain

As silts of toxicity and song

For instance track \#13 was far

2 was not listening 
From the house which we pretended

To be in

At night while sound

Clinged into our hair

I banged my head so many times

Reeled my mouth loose

We did the same

In crowds and intimacy as you

Rolled and asked me why are

Words set apart by

$S$ pace $\mathrm{S}$

Remember when i fixed your keyboard

Зر مرار that

When we would lie awake the next day

Ournecks remembered

Dance kiss throe

Do it again and

Move to the

Antipodal side

Now walk

This place could kill you

I took hands and plucked the ground

Xylene

calm carpets citifying corpses casting creeds horrifying having held her coming home hurrily habitually coming home hurrily habitually

From the depths of this vast yet finite forest

I will be kept

Under in a place

I have never walked

On still

Revolting against sleep

Until they do not

Excavate me to build

a state of affairs and flares

${ }^{3}$ so many times 
Kohl 2.1

108<smiles>[As]=[As]</smiles>

I stare and

Enter the strata while

I want to fuck this place

Fracking you under your nadir

Aaaaa your legs like stars

Relapsed in all directions

Botanical marvels scatologies

Under infrastructures built

Apartmentheid walls

with wastes i did not know

Of.

From the depths of this last yet finite forest

I imagined the places you arrive

To

When you come.

In chemical violence

$-S$

From the depths of this last yet finite forest I remember well when

I was born on the

Internet

As when someone told me,

"I have a camera"

But I love

You in many

So I want to lock myself

In this room

And a forest

Be with you forever on

Glass, mathematics and paper

Buried in light digital form.

From the depths of this sad yet finite room

My screen abducted our solar complex

Impersonal sloven connections so

${ }^{4}$ make me sway 
Slow they run and turn

Me on at night Little

Arsonist heisted my dangling

Locks in a left hand

She wrapped the curls around her neck

Incandescence

A word you repeat until your tongue

Burned.

We wished we could look at the same screen and talk to each other.

From the depths of this sad yet finite forest

My breasts flew when

Little Arsonist asked me to

Commit sardonic murder with

4 lips

a n $\mathrm{d} 15$ fingers

I went on my knees

Ate her nails

Blinker

On a weaponized earth dredged

Up, down, mucky

Architecture, love and intoxication

I spew words ay

Abolish text

With

Invisible friends.

Hamstrings Climbing Barrels' Debt

A Film Crew and a Family

Girls, hunters, wastes, wolves, a missing mountain, many forces

Political lingo very global, envyronment versus tourism

Why were wastes - secretly - installed on stones

Pronouns are assigned interchangeably ii iii iii ii

Dead form material for

Money distributed near friends

To you

i $<<<333$ wonder

Will $\mathrm{i}$ be 
Kohl 2.1

110 As cinema toxic

When dead and

Buried in

iTALLY ??

Or would

I have

Abolished language

With justice and invisible

animals. 